\title{
RUPTURA DE LA TRADICIÓN, CONSTRUCCIÓN DE LA MUJER MODERNA \\ Y RESISTENCIA DEL PATRIARCADO LIBERAL EN PANAMÁ
}

EN LAS DÉCADAS DE 1920 Y 1930

\author{
MSc. Yolanda Marco Serra \\ Catedrática \\ Departamento de Historia \\ Universidad de Panamá
}

\begin{abstract}
RESUMEN
Este artículo analiza la polémica feminista en Panamá en las primeras décadas del siglo XX y el inicio del debate sobre el sufragismo. También se examinan las ideas de algunas de las primeras periodistas feministas que escribieron en la prensa y las respuestas y resistencia del patriarcado liberal ante sus planteamientos y propuestas.

Descriptores: Mujeres. Participación Política. Feminismo. Sufragismo. Educación. Panamá. Décadas 1920 y 1930.
\end{abstract}

No más servir de instrumento de pasiones, ni de vil compañera, ni de esclava del hombre. Es necesario que el ángel del hogar llene ese vacío alternando en la cátedra, en el foro, en el manejo de la cosa pública: concurriendo a los comicios para que pueda tildarse, con razón, de populares los sufragios y de efectivas las llamadas democracias; es necesario abrirle paso, permitiéndole la educación más conveniente a fin de que adquiera como base fundamental de sus amplias aspiraciones la independencia económica, mediante la cual refulja el sol hermosode libertad en los vastos horizontes que le guarda el porvenir. (J.M..V., "Largas las ideas y los cabellos cortos", Orientación Feminista. Revista del Partido Nacional Feminista, No. 6, Mayo de 1926)

\section{INTRODUCCIÓN}

Este trabajo resume la primera parte y algunos de los principales argumentos de un trabajo previo, más amplio y recientemente publicado, el cual estudia los discursos generados acerca de las mujeres, el feminismo y el sufragismo entre la segunda y tercera décadas del 
siglo XX; es decir, en los momentos inmediatamente anteriores al nacimiento del movimiento feminista panameño y en los primeros años de su organización (Marco: 2002).

Nos referiremos al pensamiento de las primeras mujeres que, rompiendo con la tradición, empezaron a hablar y escribir para el público femenino sobre ellas mismas. Ellas cuestionaron la tradición decimonónica de la mujer circunscrita a la vida del hogar, y también el modelo de mujer que predominaba hasta entonces. Escribieron para proponer una nueva mujer, y sentaron las bases de la mujer moderna. La reacción de los hombres ante su propuesta, que estaba comenzando a cambiar también su mundo y el de las relaciones entre los sexos, es objeto también del estudio. Queremos mostrar cómo, cuando las mujeres pasaron de las palabras a los hechos y crearon las primeras organizaciones feministas y sufragistas, las opiniones masculinas se dividieron más aún y la reacción de los políticos se abrió en un amplio abanico, especialmente el discurso de aquellos políticos liberales que no supieron ir más allá de sus prejuicios y temores y se atascaron en una posición antisufragista que fue, en definitiva, la que impidió el disfrute de sus derechos políticos a las mujeres por bastantes años.

El artículo se divide en dos partes, en la primera se estudia la ruptura de la tradición, las nuevas ideas de las mujeres sobre las mujeres y el feminismo, y cómo este pensamiento empezó a modelar un nuevo tipo de mujer. En la segunda parte se analizan los discursos masculinos en el momento de la acción, cuando las sufragistas plantearon sus demandas de manera organizada y la resistencia al sufragio femenino, y al tipo de mujeres que lo reivindicaba, por parte del sector mayoritario del liberalismo.

El trabajo se ha elaborado utilizando sobre todo fuentes periodísticas, que son casi las únicas que permiten conocer el pensamiento de la gente, y también revistas y libros. Algunos 
trabajos previos, unos enfocados exclusivamente al estudio de la evolución del movimiento feminista panameño en las primeras décadas del siglo, otros orientados al estudio de la historia social de las mujeres de las décadas de los años veinte y treinta, nos permiten ya conocer mucho mejor la historia de este movimiento (Marco: 1993; 1997ª; 1997b; 2000; $\left.2002^{\mathrm{a}} ; 2002 \mathrm{~b} ; 2002 \mathrm{c}\right)$.

En las dos primeras décadas del siglo XX hasta Panamá llegaron los ecos de la transformación de un mundo en el que las mujeres reclamaban su libertad para ser y actuar, tanto en el mundo privado como en el público. El movimiento feminista y el sufragismo no sólo transformaron las leyes sobre el matrimonio y la familia, dándoles a las mujeres derechos similares a los del hombre, sino que catapultaron a las mujeres a la sociedad y a la actividad política en un proceso que culminó después del fin de la Gran Guerra cuando en Inglaterra, Estados Unidos y luego otros países las mujeres conquistaron por fin el derecho al sufragio. Y es que, después de largos años de lucha de los movimientos sufragistas, la experiencia de trabajo y libertad de las mujeres en los años de la Guerra Europea, las transformaciones culturales y científicas, la influencia del psicoanálisis, cambiaron profundamente la situación de la mujer.

En Estados Unidos, la incipiente sociedad de consumo transformó el trabajo de las mujeres en el hogar, con el crecimiento económico las mujeres entraron con más fuerza en el mundo de la educación y el trabajo remunerado fuera de la familia, el reconocimiento de la sexualidad femenina y la difusión de los nuevos medios anticonceptivos, todo ello contribuyó a redefinir la imagen de la mujer (Cott 2000: 105-126). La nueva administración doméstica (la economía doméstica), la nueva crianza de los hijos (la puericultura), el creciente papel e influencia de la publicidad en la vida de la gente, los nuevos medios de comunicación de 
masas como la radio y el cine, ayudaron a formar esta imagen y a exportarla por todo el mundo. Los roles sexuales se modificaron también como resultado de estos cambios, siendo el fundamental que quedó asentada la posibilidad de la participación social y política de la mujer.

En Europa la modernización se realizó de manera más lenta que en Estados Unidos. Este proceso significaba, en conjunto, el fin de la mujer "eternamente menor de edad" (Sohn 2000:127-157). Estas modificaciones en los roles sexuales y en el papel de la mujer no significaba, sin embargo, que no siguieran habiendo limitaciones e inequidades para las mujeres: las había en la familia, en el trabajo y en la política donde eran poquísimas las mujeres en puestos de elección popular (aunque habían más en la administración del Estado), había también más mujeres en los sindicatos que en los partidos políticos. En definitiva, como afirma Michelle Perrot, surge: “...un modelo de mujer moderna, que orienta nuestra visión del cambio de los roles sexuales en el siglo $\mathrm{XX}$ pero cuyo conformismo es tan grande como su fuerza emancipadora..." (Duby y Perrot 2000: 41).

Estos movimientos de cambio fueron resistidos por los hombres y por las instituciones creadas por el patriarcado liberal, ${ }^{1}$ que en Panamá tuvo su expresión en el Estado hasta 1946. La mayor parte de los Estados europeos “....acaba con las distinciones liberales anteriores entre lo privado y lo público, la familia y el estado, el individuo y el Estado...” (Duby y Perrot 2000: 41), cuando todos tratan más o menos autoritariamente de "nacionalizar" a sus ciudadanas, ya desplazando la maternidad al dominio público (como por ejemplo hace Suecia con su política demográfica), o bien movilizando a las mujeres para ponerlas al servicio de la patria en guerra, o regimentándolas en organizaciones consagradas a la grandeza nacional (como en el caso de los Estados nazi-fascistas). 
En América Latina este proceso tuvo su propio ritmo y características. Las repúblicas latinoamericanas nacieron lastradas por constituciones conservadoras que enfatizaban el género: el sujeto de derecho era el varón mayor de edad, dueño de ciertas propiedades, que pagaba un mínimo de impuestos y servía en el ejército. Con el crecimiento económico y la incipiente industrialización, especialmente en los países del Cono sur, ocurrieron cambios sociales y nuevas clases sociales (obreros, clases medias) adquirieron protagonismo político y plantearon demandas de reformas sociales y políticas que contemplaran sus intereses hasta entonces olvidados. En ese mismo momento, en el tránsito del siglo XIX al siglo XX, empieza también la polémica sobre el feminismo y el sufragismo. La potencialidad transformadora en esos momentos del feminismo era mayor de la que hoy podemos percibir. Lavrin se refiere a ello:

“...Feminismo y sufragismo no son equivalentes. El feminismo fue una ideología amplia que incluyó una serie de demandas de cambio o reforma social específicamente aplicadas a la mujer y a las relaciones entre los sexos. En el abanico de sus intereses se incluyó el sufragio femenino, pero también la igualdad jurídica entre hombre y mujer, y la reforma de las leyes familiares como base de una reorganización de la autoridad entre los esposos y de su autoridad sobre los hijos. Éstas eran reformas de carácter legal que demandaban cambios en los Códigos Civiles y penales. Pero más allá de las reformas legales, el feminismo era una reivindicación de la personalidad de la mujer en el campo de las relaciones humanas. Era una revaloración del significado de la palabra 'libertad' para todas las mujeres sin distinción de clases sociales, en cuanto que todas estaban sometidas a las mismas restricciones legales. Era el reconocimiento de la capacidad intelectual de la mujer como ser pensante y con el derecho la una educación tan completa como la del hombre..." (Lavrin 1999: 2-3).

Por eso, las feministas hablaban de "emancipación" femenina como se escribía acerca de la emancipación de los esclavos, porque su estado era, más que de opresión, de esclavitud dada la restricción a sus movimientos físicos, a sus deseos de hacer su propia voluntad sin tener que pedir permiso de sus padres o maridos. El debate sobre el feminismo y los derechos 
de las mujeres llevó inmediatamente al debate sobre el sufragio ya que las feministas sufragistas deseaban el sufragio para poder ejercer la ciudadanía para cambiar las premisas de las mujeres en la sociedad:

“...El cambio que se apuntaba con el feminismo y el sufragismo era de gigantescas proporciones. Implicaba nada menos que el aparato legal sobre el que se basaban todas las actividades sociales y económicas de las naciones occidentales. Se enfocaba sobre la condición de uno de los dos sexos que forma la especie humana y que predicaba a la mujer como un ser sin voz, encuadrado dentro de un espacio definido como 'hogar' o, expandiendo su esfera, dentro de ciertos perímetros de ocupaciones de trabajo y sometido a la voluntad del hombre dentro de la familia con un destino determinado por sus características biológicas..." (Lavrin 1999: 3-4).

Las sufragistas planteaban efectivamente una de las transformaciones más revolucionarias de su época, por ello la resistencia que enfrentaron fue enorme. Para reformar la situación de la mujer había que cambiar la legislación, pero también la forma de pensar sobre los papeles de las mujeres y los hombres en la sociedad. Se trataba de un proceso de cambio cultural y también eminentemente político que requería un arma política, esa arma política era el sufragio femenino que, en la época y para las mentes más liberales, se identificaba como el instrumento más potente en el proceso de democratización que fomentaban, capaz de alterar las condiciones de vida de muchos hombres y de todas las mujeres.

Panamá fue un caso especial entre las repúblicas latinoamericanas, nació como República independiente con una constitución mucho más liberal que las de las restantes naciones latinoamericanos. Sabido es que la Constitución de 1904 eliminó la referencia explícita a que sólo los varones tenían el derecho a la ciudadanía que tenía la constitución colombiana y aceptaba además el principio democrático del sufragio universal masculino, lo cual creaba una nueva contradicción ya que dificultaba enormemente la justificación de la 
discriminación de las mujeres de la ciudadanía. Fue especial también Panamá porque recibió una influencia directa de las organizaciones femeninas y del movimiento feminista norteamericanos. Pero no dejó de ser por ello una república, en la que, como en los restantes países latinoamericanos, la cultura compartida por siglos ponía en el debate sobre el feminismo y el sufragismo temas como los de la femineidad y la maternidad, con los que también las feministas panameñas se enfrentaron. En este trabajo analizaremos el proceso de construcción del movimiento sufragista, a partir de las mismas mujeres y de cómo redefinieron su identidad individual y colectiva y de la oposición que encontraron, a lo largo de casi treinta años, hasta la conquista del derecho al sufragio.

\section{LA RUPTURA DE LA TRADICIÓN Y LA CONSTRUCCIÓN DE LA MUJER MODERNA}

La fuente fundamental para el estudio de este tema ha sido la prensa escrita de la época, no ha habido otra opción ya que es casi la única en la que sobreviven los testimonios de las mujeres y los hombres de esos años. Lamentablemente, cabe destacar que fueron escasas las mujeres panameñas que han escrito memorias, o textos sobre la historia de los movimientos de mujeres de las que fueran protagonistas, o, si así hubiera sido, no han llegado hasta nosotros. Nos parece importante recordar que las opiniones y las voces que recogeremos a continuación no sólo son la expresión de quienes las emitían, sino que contribuyeron de manera fundamental a crear la realidad, una nueva realidad para las mujeres.

\section{Alma o La ruptura de la tradición}


En la segunda década de vida republicana, emergen lentamente las mujeres en la vida social panameña. Comienzan a regresar al país aquéllas que habían sido becadas para estudiar en el Viejo Continente, algunas de ellas tras poco tiempo de estadía en el país partieron de nuevo hacia Estados Unidos para completar sus estudios. Casi todas eran profesoras y llegaron a ser ayudas importantísimas en las políticas educativas nacionales. Sus voces empiezan a oírse en las escuelas y centros educativos, en los escasos centros culturales y artísticos y también en la prensa. Los periódicos y revistas les dedican atención especial y aparecen secciones orientadas para el público femenino con temas de su interés especial como la moda, la belleza, etc.

Entre las primeras imágenes de las mujeres en la prensa contamos con la sección "Vida femenina" que el periódico El Diario de Panamá, publicaba en el año $1915 .^{2}$ Esta sección era diaria, e incluía columnas que reproducían artículos de periódicos extranjeros, eso sí firmados por mujeres, y trataban temas diversos como el amor sentimental, la elegancia y la coquetería, impresiones de viaje, las mujeres y la guerra europea, la moda parisiense, la belleza femenina a través de las épocas, etc. ${ }^{3}$ Las referencias de las actividades del feminismo internacional también estaban reseñadas, por ejemplo el congreso internacional feminista de noviembre de 1915. ${ }^{4}$ Es interesante una propuesta de una lectora que aparece publicada para que se abriera una sección especial para que las mujeres pudieran consultar cuestiones de su interés en ella, la persona proponente (que no firma, aunque se identifica como mujer) señala también que se pudiera escribir bajo pseudónimo, ${ }^{5}$ lo cual muestra tanto el interés de algunas mujeres de poder hablar de lo que les interesa como el miedo de ser reconocidas para lo cual se pide la posibilidad del anonimato. Aunque las mujeres del país no escriben todavía, y los temas tratados en su mayoría son de carácter tradicional, ligados a la imagen de mujer del hogar y 
sin mayores intereses en la cosa pública, ya aparecen, sin embargo, temáticas nuevas como la influencia de la guerra europea en la vida de las mujeres de aquel continente, y reseñas de las actividades de las mujeres organizadas. Podemos inferir también que estos artículos eran leídos por un grupo significativo de mujeres ya que, como vimos por la lectora de El Diario de Panamá mencionada arriba, las mujeres panameñas sentían la necesidad de tener una voz y una expresión propia. ${ }^{6}$

Según el testimonio de Guillermo Patterson, hacia 1920 se publicó una revista feminista llamada La mujer panameña y existió el proyecto de creación de otra denominada Actividades femeninas a comienzos de 1923 (que, al parecer, nunca salió). Lastimosamente parece que se han perdido para la memoria histórica estos documentos, a menos que algún día aparezca algún ejemplar perdido en alguna biblioteca o archivo.

En 1919, existe ya la "Sección femenina", firmada bajo el pseudónimo de Alma, que tiene periodicidad semanal (aparece cada domingo). No sabemos cuándo comenzó a publicarse ni cuanto tiempo duró porque no existe en ninguna de las hemerotecas de la ciudad la colección completa del periódico. La persona autora de "Sección femenina" se identifica siempre como mujer. Aunque no tengamos la certeza absoluta sobre su identidad real, basándonos en el testimonio de Guillermo Patterson Jr. y en el de María Isabel Mendoza, pensamos que Alma pudiera haber sido Enriqueta R. Morales. ${ }^{7}$ Morales tenía en ese entonces 28 años, había realizado estudios de enfermería en Bruselas y el ambiente de revolución social que se vivía en la Europa de preguerra contribuyó a definir sus ideas en pro de reformas de carácter feminista y social, a lo que se sumó su posterior estadía en Washington (desde 1912 a 1916 su padre fue el embajador del gobierno panameño en los Estados Unidos) y las experiencias que allí vivió tanto relacionadas con la guerra europea como con las luchas y 
organización de las feministas norteamericanas. Hay que recordar también que la influencia paterna (no sabemos mucho de la madre) debió jugar sin duda un papel importante en sus ideas y sus actividades profesionales y sociales. Eusebio A. Morales, su padre, no sólo fue un liberal en el sentido mejor de la palabra, hombre tolerante y demócrata incluso, sino que su apertura ideológica y su auténtico interés por hacer verdad los principios igualitarios preconizados por las grandes revoluciones liberales le llevaron a defender las ideas socialistas, aunque no la forma de gobierno que asumieron con la revolución bolchevique, su pensamiento actualmente se podría considerar cercano a los planteamientos socialdemócratas.

Los temas de los artículos de Alma son variados y nos permiten tener una visión amplia de los intereses, el sentir y las ideas de, al menos, un sector de las mujeres sobre asuntos candentes del momento. Alma ataca la actitud femenina, no ya la tradicional sino la de las mujeres educadas y profesionales de la época de limitar sus intereses y campo de acción a los trabajos en el hogar y los de su profesión, propugnando la participación de las mujeres en la solución de los problemas sociales. En su concepto de mujer, ésta debe ser una luchadora por el bienestar social, tan fuerte como el hombre, aunque de manera distinta, es decir: no una carga sino una ayuda, no muñecas de entretenimiento sino cooperadoras y fieles salvaguardias porque, afirmaba que

“...si ellos poseen cerebro, nosotras también lo poseemos; si ellos constituyen la fuerza, nosotras formamos el corazón; mientras la fuerza crea la materia, el corazón la purifica. Ellos como fuertes y enérgicos se ocuparán del engrandecimiento material de nuestra tierra, a nosotras corresponde engrandecerla espiritualmente. En tanto ellos construyen caminos, levantan edificios, cultivan la tierra, explotan los bosques, forman las leyes y administran los intereses sociales, a nosotras toca proteger a la infancia, educar a la adolescencia, salvar a la juventud y culturizar en toda forma nuestra patria..." (Alma 1919a). 
Las actividades sociales que les propone a las mujeres son: atacar el vicio (el alcohol y el juego), fomentar el estudio (fundando bibliotecas populares, fomentando los juegos deportivos), para “...velar por la conservación de nuestra raza, a fin de formar hombres y mujeres robustos...", propone también el fomento del ejercicio saludable, el cuidado de la higiene del lenguaje y la conservación de las tradiciones (aunque no, por lo visto, la visión tradicional decimonónica de la mujer), “...en fin, dice practiquemos la caridad espiritual, sin favorecer el vicio ni fomentar la pereza..." Se refiere también a la moda en un sentido amplio, criticando a las marisabidillas ignorantes que hablan de todo y no saben nada, afirma que no hay nada mejor para la mujer que la naturalidad y la sencillez, virtudes que deben inspirar todos los actos de la vida de la mujer. Pero esos valores estoicos no son sólo para las mujeres, sino para todo el mundo, aunque en el caso de las mujeres hacen que desaparezca la afectación, y que “...brillen la bondad y la razón, normas únicas a las que debe sujetarse su conducta..." (Alma 1919a).

En el artículo "Un paso adelante" expresa su alborozo por la entrada de mujeres en el Liceo, la Normal del Instituto Nacional y la Escuela de Derecho y Ciencias Políticas porque se ha roto una barrera y ya la actividad profesional de las mujeres no estará limitada, como antes, a los estudios pedagógicos. Esta medida es necesaria para la autora que piensa en la "sacra bandera de la igualdad" de ambos sexos. Se refiere a los temores de quienes piensan que de la convivencia de ambos sexos "puedan surgir relaciones indebidas". Al igual que los demás defensores de la enseñanza mixta, Alma dice que ése es un prejuicio vano, que no tiene lógica natural la separación de los sexos que, por otra parte, conviven en la familia, lo que va a pasar es que se acostumbrarán a vivir en saludable compañía, sin la malicia de los adultos, aprenderán los hombres a estimar y respetar a las mujeres y las mujeres aprenderán a ver en el 
hombre su defensor. Aprovecha la oportunidad para animar a las mujeres a no desaprovechar la oportunidad, reconociendo que son muy valerosas las que así lo hacen, ya “...que no dan oídos a la maledicencia, demostrando que por encima de sus vaticinios está nuestra fuerza para hacernos respetar en este tiempo y bajo toda circunstancia...” (Alma 1919b).

Otra muestra de su pensamiento muy interesante es el artículo titulado "La tolerancia", que es una muestra del pensamiento liberal y un pequeño tratado de ética para las mujeres. En él la autora explica cómo debe ser la tolerancia para las mujeres: no complicidad con las faltas de los demás sino “...tolerancia racional que ayuda a corregir al que yerra...” Sólo los seres bondadosos y morales pueden ser tolerantes, los autoritarios e intransigentes, que no perdonan al prójimo, tratan siempre de reprimir a los demás (justamente en aquellos defectos que ellos mismos tienen) y son incapaces de actuar de forma tolerante. La tolerancia se ejerce con las conductas erradas, no con el vicio, ya que “...el error es una equivocación sufrida por una persona consciente y todos somos susceptibles de equivocarnos..." Para Alma, la mujer, como "modeladora de almas", es quien más tiene que enseñar la tolerancia, pero no en el ámbito sólo de la familia sino en toda la sociedad. La mujer como elemento moralizador de la sociedad debe también ayudar al rescate del valor del lenguaje en la educación, llama al cuidado de su pulcritud y hace un llamado a los adultos a que cuiden su lenguaje frente a los niños, e invita a la prensa y a las damas a abrir una campaña en pro de la regeneración del lenguaje (Alma 1919c).

El título de su artículo "La salud como base de la belleza" es muy explícito. Alma afirma que la higiene va destronando a la moda, pero todavía hay mujeres que utilizan medidas contraproducentes como el "estrechamiento exagerado del corset", y otros que atentan contra la salud. La belleza es la salud, que da “...frescura, colorido, brillantez al 
rostro, lozanía y morbidez a las formas y, en general, ciertas dosis de energía y fortaleza al organismo para mantenerlo apto para el desempeño de todas sus funciones..." (Alma 1919d). La idea de que la delgadez le da a la mujer delicadeza y femineidad y más encantos es falsa, lo mismo que la teoría de que la robustez y el vigor la masculinizan. Y, muy imbuida de las ideas higienistas y eugénicas de su época, subraya que la salud robustece y desarrolla el físico de las mujeres, para hacerlas aptas “...para dar a la patria hijos sanos y robustos, llenos de salud y de vida..."

Pero, además, la higiene del espíritu es tan necesaria como la corporal para la conservación de la salud y el mejoramiento de la especie. Hay un correlato entre el cuerpo y el espíritu, lo que le pasa a uno afecta al otro, y viceversa. Tónicos del espíritu son las saludables lecturas, el ejercicio continuo en obras útiles y alejar los malos pensamientos que son enemigos de la tranquilidad espiritual. Los malos pensamientos

“...son originados por la envidia, el odio, la ira y otras bajas pasiones que crean ciertos productos químicos que, además de destruir la naturaleza moral del individuo, menoscaba la salud en tanto que los pensamientos nobles, hijos de la bondad, cristalizada en cualquier forma, producen el efecto contrario..."

La verdadera belleza física, por lo tanto, es la “...constitución física sana, rostro coloreado por la salud, sonrisa ingenua reflejo de bondad, en un carácter jovial y alegre...", a lo que se añade la cultura intelectual y otras cualidades que contribuyan a enaltecerlas. El carácter de una mujer puede definir su futuro en muchas ocasiones. A veces, dice la autora,

“...pasan por mujeres de buen carácter las que precisamente carecen de él y anulan su personalidad para plegarse servilmente a los deseos y caprichos de los demás, estas mujeres sin opinión, sin iniciativa propia, incapaces de reaccionar, podrían ser denominadas entes irracionales pues fácilmente pueden inducirlas al bien o al mal ...Generalmente son éstas las preferidas por el hombre vulgar por su debilidad, 
incapacitadas para protestar ante la injusticia, el oficio que estas mujeres desempeñan en la vida es sólo la sumisión y el servilismo..."

Otro tipo de carácter femenino, es el de las que erróneamente se llama mujeres de mal carácter, aquéllas que tienen ideas propias y luchan por realizarlas aunque emplean a veces medios inadecuados, influidas sin duda por ideas de superioridad, que tratan de dominar a la fuerza a cuantos las rodean. Éstas poseen la materia prima del carácter pero no ha sido barnizado siquiera por la cultura intelectual.

Otro tipo de mujer que existe es la excéntrica, cuyo carácter es el resultado de sus caprichos. Alma se pregunta cómo encontrar un carácter superior en la mujer, si ha sido criada entre “...maléficos prejuicios, influida por otros espíritus y subordinada bajo el mandato de sus superiores, que lejos de liberarla y enseñarle a conquistar su independencia la esclavizan no permitiéndole ejercitar su criterio ni encauzar por sí sola sus acciones...”. Frente a tales obstáculos, cuando se encuentra una mujer superior "hay que rendirle admiración e imitarlas". ¿En qué consiste la superioridad del carácter femenino? La superioridad del carácter femenino consiste en

“...la firmeza e integridad de sus ideas, en un espíritu sereno, inundado de sana alegría, que sabe pesar sus pensamientos y acciones en la balanza de su razonamiento, en un alma que, provista de cierta dosis de ternura, confiada en su bondad, protegida por la coraza de su propio dominio, se lanza a la conquista de sus ideales, donde casi siempre llega a vencer por el poder de su ternura y la influencia de su cerebro... [Termina afirmando, que] ....sin duda alguna, el destino de la mujer está en sus propias manos. El poder de ella depende en gran parte de la formación de su carácter. Consigamos modelar bien a éste y conseguiremos muchos éxitos en la vida..." (Alma 1919e).

El tema de la familia y el hogar ocupan un lugar destacado en las reflexiones de Alma, en "La mujer en la intimidad de la familia" plantea que la mujer tiene la clave de la armonía familiar. Con la razón debe estudiar con calma los problemas domésticos en sus múltiples 
manifestaciones, con la ternura debe "subyugar el corazón humano", que le granjeará el respeto y cariño de la familia. Con tacto y con discreción, “...a fuerza de ternura y razonamiento, sin hacer violento su dominio, está palpable por doquiera...” Estudia diversos tipos de comportamientos femeninos en la intimidad familiar: las mujeres que son admiradas en sociedad pero son insoportables y odiosas en su familia; las que abusan de su familia quejándose todo el tiempo "con actitudes ridículas, antiestéticas, y a veces hasta groseras casi”; otras, ataviadas elegantemente en público, en casa son un desastre.

La mujer modesta sin ostentaciones sabe reunir siempre en hermosa trilogía la pulcritud de su persona, de su vestuario y de sus modales. En otro de sus artículos “...trata sobre la felicidad como aspiración humana en el ámbito de la pareja conyugal...” En su opinión, sólo la tranquilidad individual hace la doméstica, que conduce a la armonía conyugal. Ahora bien, esta armonía sólo puede mantenerse permanentemente si existe un lazo indisoluble de afecto verdadero entre los cónyuges y compenetración moral e intelectual de los cónyuges. También la mujer es la que tiene la clave de la felicidad conyugal en sus manos, que es la ternura, si además llegara la mujer a compenetrarse con el hombre en todos sus ideales y luchas sería su mayor triunfo: “...vencer al hombre por el doble poder de su ternura y de su espíritu..." (Alma 1919e).

Alma también se refirió a otros temas de actualidad como a la influencia del cinematógrafo y su influencia, celebrando el papel de la ciencia en el progreso de la humanidad y la apertura de nuevos campos hacia el perfeccionamiento, sin embargo, dice, el cinematógrafo que en sí mismo es neutro puede propagar vicios y males, puede despertar la naturaleza sexual en algunos jóvenes, y puede llevar a la imitación de conductas inadecuadas por lo que propone que el alcalde prohiba la asistencia de niños y adolescentes al 
cinematógrafo en la noche y que se hagan sesiones especiales para ellos de carácter moralizante y educativo. También la economía doméstica es objeto de su atención, y de sus alabanzas.

La mujer que propone Alma como ideal es la que usa su cerebro, su capacidad de raciocinio tanto como la ternura de su corazón, a lo que suma la virtud de purificar que tiene cuando actúa así. Esa mujer es tan fuerte como el hombre, tan luchadora por sus ideales como él y sabe hacerse respetar. Es cooperadora con su compañero y no sólo se desenvolverá en su hogar y en su profesión sino que participará en la solución de los problemas sociales, luchando por el bienestar social, se ocupará del bienestar de la infancia, de la educación de los adolescentes y de la juventud y, además de todo esto, de culturizar a la patria. Poseerá una gran caridad espiritual, cultura intelectual y gran capacidad de trabajo. La base de su belleza será la salud, la naturalidad y la sencillez, la modestia sin ostentaciones. La firmeza e integridad de sus ideas junto con su autodominio harán de ella una persona con opinión propia, lo más alejado a la mujer servil del pasado. Para formarse tal carácter femenino, requiere de las mismas oportunidades que el hombre, partiendo de la igualdad en la educación (coeducación). Con relación a la familia, esta mujer tiene la clave de la armonía doméstica y conyugal, la que puede unir a una pareja toda su vida; para Alma, sin embargo, la armonía sólo es posible si se parte de la tranquilidad individual, sólo así la mujer estará capacitada para, con racionalidad, ternura y compenetración con su compañero, hacer posible la armonía doméstica y conyugal. Es un modelo de mujer ilustrada con un fuerte componente de valores éticos. 


\section{Lola Collante, otro modelo de mujer moderna}

Lola Collante es probablemente la primera mujer periodista de Panamá. Seguramente, ella no pudo vivir de su escritura, pero es más que probable que sus escritos le ayudaron a sobrevivir. Llegó al país procedente de Colombia (al parecer de Barranquilla) alrededor de 1917 o 1918, con un hijo de corta edad. Aunque a veces se dice de ella que estaba divorciada, no parece muy probable ya que en Colombia el divorcio no ha sido legal hasta años muy recientes, probablemente era madre soltera. Según testimonios de coetáneos ${ }^{8}$, se convirtió en una especie de musa de la juventud intelectual y "de avanzada" de esos años, y era muy admirada y respetada por lo más intelectual de la juventud bohemia que militaba en la Federación de Estudiantes de Panamá y en el Sindicato General de Trabajadores. Escribía en los periódicos del país y probablemente para otros del exterior. Hacia la mitad de los años veinte se casó con el abogado Alejandro Tapia y, aunque su vida dio un giro importante, siguió escribiendo y publicando artículos y poesías en revistas y periódicos a lo largo de toda su vida.

La obra periodística de Collante es variada, escribe sobre política colombiana, sobre América Latina, sobre literatura por supuesto, y sobre otros muchos temas de la actualidad panameña e internacional. Algo que llama extraordinariamente la atención de ella es que se trata de la primera mujer en escribir en los periódicos sobre política nacional e internacional. Un testimonio literario dibuja un retrato de ella que la describe como mujer sin prejuicios sociales, generosa,

“...que lucha en ardiente colisión por reconquistar la dignidad perdida de los pueblos y que golpea con sus delicados puños contra los sagrados muros de la civilización, ... [que levanta el rostro y se empina gallarda] ...para ver más allá hacia la renovación, que tiene por labor "reencaminar por derroteros de progreso y de bien a las democracias...; la que tiende al refinamiento de la educación femenina y que se 
consagra a modificar el sistema de infundir respeto y amor a la Patria". [Termina diciendo:] ...Lola Collante es un alma hecha para la lucha de las ideas ...Y no es que sea una alma rebelde, no. Antes bien, es delicada, buena: un alma pensadora y contemplativa..." (Delgado 1921).

Un tema que provocó la atención de la periodista fue el de la transformación del aspecto físico de las mujeres. Defendió la moda que se estaba introduciendo entonces: la simplificación del vestido, la eliminación de los grandes sombreros, el cabello corto, la sustitución de los tacones inverosímiles, y, por supuesto, la supresión del corsé. Todo ello para que la mujer moderna, que iba a la universidad y al trabajo, pudiera hacer sus actividades de manera más práctica. Opinaba que algún día las mujeres prescindirían del maquillaje o lo limitarían por las mismas razones prácticas, y no entendía porque algunas personas le daban tanta importancia a estos cambios (Collante 1925).

Collante publicó varios artículos en la revista Cuasimodo en el año 1920, uno de ellos dedicado a las mujeres latinoamericanas titulado "Al oído de mis hermanas de América”, en el que con pasión las incita a liberarse. Su argumento central es que ya la mujer está emergiendo de sí misma como es, ya no responde a la imagen tradicional y multifacética que la dibuja como la esfinge, la bruja, o el animal perverso, seductora siempre. Según ella, lo que la mujer nueva quiere es muy razonable, trata simplemente de alcanzar su autonomía moral, autonomía que, por otra parte, redundaría en una maternidad más responsable. Les dice:

“...¿o sentís que vibra en vosotras un temblor de tímidas alas ignoradas, ...no sentís que por sobre todas las ficciones late una inmensa verdad que precisa descubrir y seguir? ¿Sois débiles? ¿Sois pequeñas? ¿Sois triviales? ¿Sois caídas? Recogeos al fondo de vosotras mismas y removed los tesoros escondidos que todas poseemos y aprended a hacer de un grano de arena una roca, y de una roca un baluarte...” (Collante 1920a). 
En el articulo "Cómo habrá escrito Nietzche sobre la mujer moderna?", se pregunta cómo pudo decir tal genio las cosas que escribió sobre las mujeres, piensa que difícilmente podría acusar a las mujeres modernas de zánganos y de mantenidas por los hombres, y en su argumentación afirma que fueron los hombres (más fuertes y poderosos que las mujeres) los que convirtieron (por su vanidad y ambición) a las mujeres en objetos de placer y superficialidad, pero el verdadero ser de la mujer es otro, así que “...mientras los hombres corrían como desorbitados hacia la muerte, las mujeres abandonaban las posturas lánguidas, cambiaban el gesto de viñeta y corrían a ocupar los puestos de los hombres, sin timideces ni peligrosas coqueterías, sin rastro de afectación..." (Collante 1922). Observemos la enorme trascendencia que tuvo para miles de mujeres, ya no sólo en Europa sino en todo el mundo, la experiencia de las mujeres europeas durante la Gran Guerra. Y sigue diciendo, “...cada día, cada hora, el afán de la mujer moderna es adquirir su independencia y su libertad, base firme de la libertad amorosa que coloca a la mujer en el terreno de la libre elección por simpatía..." (Collante 1922). La libertad amorosa (aunque no llegue a hablar del amor libre) es una posibilidad para la mujer moderna, que no podía tener antes. Seguramente, piensa, si Nietzche conociera a estas mujeres, no escribiría lo mismo que escribió en sus tiempos.

Su artículo sobre el "Socialismo en Colombia" (Collante 1920b), es un apasionado escrito en el que la autora arremete contra los que niegan la existencia de graves problemas sociales en Colombia. Es un texto de denuncia las condiciones de trabajo y vida de los obreros en Colombia, de su explotación y se lamenta de la insuficiente respuesta de ellos. En "Desde la tribuna de Cuasimodo", Collante escribe sobre las mujeres, especialmente sobre las mujeres de Centro y Sudamérica, con “...la sana y vehemente intención de hacer llegar hasta ellas un rayito de sol de la vida universal que ilumine su mente, las más de las veces tan pequeñita y 
oscura como los cuartos de los pobres en las ciudades grandes..."(Collante 1920c). No cree que sean los hombres los más adecuados para estudiar y escribir sobre las mujeres, porque están obsesionados por la eterna "fémina" y escriben bajo esa influencia. De las mujeres dice:

“...Nunca humana creatura se vio más doblegada y más sujeta a trabas que la mujer", padres, abuelos, maestros, ambiente, la Iglesia... todo conspira en su contra, todos cooperan para deprimir y estupidizar a la mujer suramericana. Las mujeres francesas han tenido que luchar rudamente para asistir a clases en la Universidad de París, mientras que a las mujeres del "continente estúpido", [como ella lo llama] ...ni para la vida del puchero, de la cuna y del biberón nos han sabido preparar", tienen todavía que aprender eso para luego desandar lo andado y romper luego "los espesísimos muros de sombra..." (Collante 1920c).

En ese mismo escrito, Collante critica en su parte final a los dirigentes obreros, falsos apóstoles del patriotismo, que responden negativamente a la invitación del dirigente obrero norteamericano Gompers, para colaborar en la obra de emancipación de las clases oprimidas colombianas, porque Colombia “...tiene un resentimiento antiguo con los Estados Unidos que les veda aceptar tratos amistosos con los obreros de allí..." (le contestan), aprovechándose de la ignorancia de los “...mansos obreros que allá en la república del Corazón de Jesús, rezan aún el rosario y se amarran los pantalones con un cordón de San Francisco..." (Collante 1920c). Sus ácidas críticas contra la Iglesia son otra característica inusual y atrevida de sus escritos. En su artículo "Panamericanismo" cuestiona que la actitud de los Estados Unidos sea la mejor para buscar su solidaridad, nada ha realizado que indique su deseo y buena voluntad de iniciar una era de respeto mutuo y concordia general (Collante 1920d).

Lola Collante constituye en sí misma el modelo de mujer nueva que sería reivindicado por Alma también, aunque ambas tienen diferencias. Las coincidencias estarían en que ambas desean para la mujer: libertad (auténtica, que viene de la íntima autonomía moral), independencia en su vida, sin prejuicios sociales, generosidad, delicadeza y bondad, reflexión. 
Algunas de las diferencias vendrían porque mientras Alma propone un modelo de mujer con una actitud estoica ante la vida y valores que se corresponden con esa filosofía de la vida, Lola Collante tiene una opción vital de otro signo, mucho menos estoico. Ambas, de formas distintas, son apasionadas y escriben en los periódicos, aunque la una no se considere profesional del periodismo y la otra sí, y ambas escriben no sobre temas "de mujeres" sino sobre una gama muy diversa, aunque Lola Collante escribe sobre política directamente y no así Alma. Ambas son luchadoras sociales a su manera y le proponen a las mujeres serlo también, sin temerle a los prejuicios sociales. Alma escribe casi exclusivamente para las mujeres, mientras que Lola Collante escribe para las mujeres y los hombres, y, en algunos artículos especiales, sólo se dirige a las mujeres. Ambas son atrevidas y a la vez racionales. Mientras Alma representa una opción política liberal, Collante viene a ser la opción política de izquierda y más atrevida al plantear algunos temas (como el de la libertad amorosa, o su anticlericalismo).

Se podría haber mencionado aquí a otras mujeres que representan, por sus escritos y por su vida, la ruptura de la traición: Esperanza Guardia de Miró, que escribió en los periódicos también (a veces bajo el pseudónimo de Clara); Angélica Chávez de Patterson, cuya obra escrita es imprescindible conocer para entender en su dimensión completa el ideal de mujer que proponía el feminismo panameño (Marco 1997b), y, por supuesto, a Clara González. Sin embargo, seleccionamos a Alma y a Lola Collante primero porque escribieron sobre una gran diversidad de temas y, en segundo lugar, porque son dos de los primeros testimonios femeninos que hemos detectado mucho antes de que surjan las organizaciones feministas y proliferen entonces las voces y los escritos de mujeres. Ellas escribieron en los momentos 
precedentes al nacimiento del feminismo organizado y muestran las inquietudes y las aspiraciones de las mujeres que las llevaron a organizarse.

\section{LAS MUJERES Y EL FEMINISMO VISTOS POR LOS HOMBRES. LA} RESISTENCIA DEL PATRIARCADO LIBERAL

Para mostrar la visión que se tenía desde la posición masculina sobre las mujeres y el feminismo, hemos recurrido a las opiniones vertidas en la prensa, uno de los pocos testimonios que tenemos de ellos y el que, sin duda, muestra las posiciones más representativas del conjunto.

El editorial titulado "El feminismo de la mujer latina", firmado con las siglas J.J.D., de El Diario de Panamá, el autor sostiene que las mujeres latinas son superiores a todas las demás por su espiritualidad, que demuestra su exquisita femineidad (El Diario de Panamá, 21/7/1919). Sus atributos son la sensibilidad innata, emoción y simpatía. Por ello, dice el autor, el feminismo ha sido y es en los países latinos muy distinto a los demás. Es más mesurado, más intelectual, y, sobre todo, más femenino que el de Inglaterra o Estados Unidos. El editorialista se manifiesta partidario de las ideas de la española María de Maeztu que defiende un feminismo moderado, que, según ella, permite progresar a las mujeres más que si hubieran adoptado otro sistema, como tirar piedras y quebrar ventanas al estilo de las sufragistas inglesas, ya que de haber empleado la violencia los hombres se hubieran opuesto a sus reivindicaciones, como no ha sido así gran número de ellos apoya la emancipación

femenina. ${ }^{9}$ El feminismo de Maeztu tampoco es político, sino que se ha preocupado de mejorar a la mujer en el ámbito cultural y educativo. Según J.J.D., también la campaña reciente de las sufragistas francesas pidiendo el voto se caracterizó por la moderación que él 
alaba. Concluye el editorialista diciendo que probablemente las mujeres hispanoamericanas están transitando por el mismo proceso emancipatorio que españolas y francesas y que, por este camino, cuando el día de mañana estén preparadas suficientemente y reclamen sus derechos políticos nadie se los podrá negar.

En el artículo firmado por José Napoleón (que parece un pseudónimo), titulado "Por las mujeres", el autor pide que la Asamblea le dé sus derechos a las mujeres, pero no la igualdad "absurda" que "proclama la actual demagogia feminista". Su posición es la de que los derechos de la mujer no deben “...estar en pugna con las condiciones orgánicas de ésta...”, lo cual no significa que la mujer deba ser esclava, ni la sierva que aparece en los Códigos colombianos, debe ser igual en derechos al hombre pero con atribuciones de índole distinta. Y esas atribuciones son las de encargarse de la educación de los ciudadanos. La mujer debe mantenerse en una posición adecuada, no convertirse en marimacho ni llegar a ser sierva o protegida, cuando actúa como ciudadana tiene el derecho a las mismas prerrogativas que el hombre, propone por lo tanto que el Código civil elimine normas que atentan contra su pudor.

Para el autor, atentan contra el pudor femenino cosas como, por ejemplo, el artículo del código civil que dispone que para que la mujer pueda pedir el divorcio debe probar el concubinato escandaloso del hombre, lo cual es injusto, ya que debería bastar la voluntad de la mujer para que se le otorgase. El articulista reconoce que la situación de la mujer es de inferioridad, y que esa inferioridad deviene de su maternidad y su posición en el matrimonio, donde la prioridad del hombre es natural. Según el autor, dada la naturaleza pudorosa y la delicadeza de la mujer, para un caballero es obligante su voluntad, fuera esa la que fuera ( $E l$ Diario Nacional, 6/9/1920). 
El editorial "El feminismo", que aparece sin firma, da continuidad al debate sobre el feminismo. El autor afirma que ya la teoría de la inferioridad de la mujer está derrotada por doquier. Lo que hay que debatir es que, habiendo diferencias entre hombres y mujeres (irrebatibles ante la evidencia de que unos y otras destacan en ciencias y actividades distintas), estas diferencias no significan inferioridad de las unas frente a los otros. En la política, la mujer es más apta para la fase de propaganda, que habla más al corazón que al cerebro (afirma el editorialista), mientras que el hombre es más habilidoso para la fase intelectual de la política (preparación, análisis de las necesidades). La participación de las mujeres en política en países como EEUU comprueba que las mujeres no han cambiado: se siguen dedicando además a la infancia, la familia y actividades sociales, con ello se rechaza la idea de que, si las mujeres se dedicaran a la política, abandonarían el hogar. Concluye diciendo, que “...cuando los hombres seamos capaces de ver en la mujer una compañera orgánicamente constituida, de material igual al nuestro, entonces se habrá derruido uno de los más formidables baluartes de la esclavitud..." (El Diario Nacional, 5/12/1920).

Las ideas que sobresalen de estos escritos componen un retrato femenino ideal en el que la característica más sobresaliente es la femineidad, entendida como la sensibilidad innata, la emoción, la simpatía (como afirma uno de los autores). De la femineidad se desprende la superioridad espiritual de las mujeres, y también las características de moderación, mesura, desapasionamiento, y no violencia del feminismo latino. Todos los autores mencionados antes coinciden en esa visión sobre la femineidad. Todos sienten horror ante la posibilidad de la violencia femenina, de ahí su rechazo del sufragismo inglés y norteamericano más radical. Alguno expresa la opinión de que la igualdad en derechos se debe adecuar a las atribuciones distintas que existen entre hombres y mujeres, es decir, siendo iguales, hay una desigualdad 
natural entre ambos sexos dado el papel que por naturaleza les corresponde: la inferioridad de la mujer nace de la maternidad y se establece por lo tanto dentro del hogar a causa del papel que ésta le confiere. Nadie niega la igualdad en derechos de que ambos deben gozar, pero los éstos se adecuarían a las diferencias entre ambos sexos. La aceptación de la igualdad no significa el cuestionamiento de la "naturalidad" de la división sexual del trabajo, ni por lo tanto de las diferencias entre hombres y mujeres, de ahí el énfasis en el tema de la femineidad y la maternidad. No ha aparecido todavía a debate el tema del sufragio femenino.

\section{El debate sobre la coeducación}

Las discrepancias más relevantes sobre las mujeres y sus derechos se centran en 1919 y los años siguientes en el tema de la coeducación, incorporándose hacia 1922 el del sufragio femenino, quizás porque es la primera acción que se lleva a cabo bajo la premisa de la igualdad entre los sexos. A principios de 1919 el gobierno nacional decreta la coeducación en todos los niveles de la enseñanza en el país. Tal medida es celebrada por las mujeres que tienen opinión en la prensa, como Alma en su columna de El Diario de Panamá. Este mismo periódico publica varias notas editoriales celebrando esa decisión gubernamental y mostrando una grata sorpresa ante la cantidad de mujeres que ese mismo año se matriculan en el Instituto Nacional, lo cual interpreta el editorialista como una opción profesional práctica de parte de las mujeres. El Diario de Panamá en esa etapa es, sin duda, el representante del mejor pensamiento liberal panameño, es dirigido por Eusebio A. Morales y Ricardo A. Morales y tiene como gerente general de la empresa a José D. Moscote, todos ellos muy comprometidos con el desarrollo del feminismo en Panamá ya desde esa época. ${ }^{10}$ 
Otras personalidades destacadas de la secretaria de instrucción pública declaran sus razones a favor de la coeducación desde este mismo periódico, como José D. Crespo. Algunos de los argumentos a favor son la igualdad de derechos de las mujeres y la necesidad de devolverle su naturalidad a lo que la naturaleza no ha separado. María E. de Bernal, directora de la Escuela de Los Santos, defiende la continuidad de la educación familiar, donde hermanas y hermanos conviven y reciben la misma instrucción, aunque, señala, es fundamental, para que tal medida sea exitosa, la habilidad y responsabilidad del maestro o maestra.

T.R. Céspedes publica en este mismo diario las conferencias que impartió bajo el título muy significativo de "La coeducación como medida salvadora para nuestra sociedad", cuyo argumento central es que a la mujer se la ha educado mal, descuidando todo lo concerniente a su papel de hija, esposa y madre, por eso las niñas, sobre todo en el interior del país, salen de la escuela sin saber el papel que les corresponde desempeñar en la sociedad. De ese desconocimiento femenino de su papel social y familiar causado por la mala educación, se concluye luego que las mujeres son inferiores en todos los ramos de la vida, nada más absurdo, declara el autor: como bien ha demostrado la guerra europea, las capacidades intelectuales y habilidades son iguales en hombres y mujeres, diferenciándose en ambos sexos las individualidades. De nuevo aparece el tema de la maternidad como factor que justifica la igualdad en la educación de las mujeres, por ser estas educadoras de ciudadanos y el de la educación de la mujer como factor del progreso social. Concluye sus argumentaciones afirmando que

“...para que este progreso venga es imposible prescindir de la mujer, su participación en la lucha emprendida contra la ignorancia es valiosísima, basta considerar que ella es la madre del ciudadano, la encargada de la educación primera, la más importante en su 
desarrollo psíquico .... Si queremos que el sistema de la coeducación sea verdaderamente productivo entre nosotros debemos ante todo y sobre todo despojarnos de toda insana precaución y estar confiados en que él traerá la redención a este pueblo..." (El Diario de Panamá, 5/8/1919).

Uno de los promotores y principales defensores de la coeducación fue el mismo secretario de instrucción pública, Jeptha B. Duncan, quien explicó sus bondades y la defendió en diversidad de tribunas, discursos, artículos periodísticos y en la memoria del ramo de instrucción pública de 1920. En la revista Cuasimodo, apasionado medio de comunicación defensor de los derechos femeninos y la igualdad en la educación, Duncan defiende la idea de que la mujer es un factor social de primera importancia y la necesidad de prepararla con las mismas oportunidades que tienen los hombres. Después de la guerra europea no es posible defender otras ideas, y además la mujer, afirma en su artículo "El aspecto social de la coeducación", “...está resuelta a no perder los frutos de su triunfo...", tal como han dejado claramente sentado en su reunión en Washington más de 700 mujeres reunidas allí, se trata del esfuerzo de muchas mujeres por muchos años, y que son más vigorosos aún en el presente (Revista Cuasimodo, No. 1, Junio de 1919).

La oposición a la coeducación partía de los sectores conservadores de la sociedad y la política nacional con crítica muy duras y con agresiones muy fuertes a las mujeres que se atrevían a desafiar las convenciones. Esta oposición gozaba del decidido y poderoso apoyo de la Iglesia católica. Monseñor Guillermo Rojas y Arrieta, obispo de Panamá desde el año 1912 hasta 1926 y primer arzobispo de Panamá desde ese año, jugó un importante papel de oposición a algunas de las más significativas leyes liberales fruto de los nuevos Códigos Nacionales que se empezaron a regir a partir de 1917, como la ley de la obligatoriedad del matrimonio civil (que se modificó en 1919, reconociendo los matrimonios celebrados por las 
iglesias debidamente registradas), la ley del divorcio y la ley de coeducación. La campaña de la Iglesia católica fue muy dura, llegando incluso el arzobispo a excomulgar a todos los diputados que dieron sus votos a las leyes de matrimonio civil y del divorcio. Las publicaciones de la iglesia y los periódicos conservadores como El Pueblo y El Panameño fueron vehículos de las manifestaciones de este sector de la población, que no se limitó a protestas verbales sino que realizó manifestaciones hacia la presidencia de la República y la Asamblea en diversas ocasiones.

Uno de los portavoces más importantes de esta oposición fue el educador Nicolás Victoria Jaén (Muñoz 2001). La oposición contra la coeducación era considerada parte importante de la lucha más amplia contra la laicización de la enseñanza, y vivió una segunda etapa de auge en la presidencia de Chiari, en la cual arreciaron las protestas. Desde las páginas de El Pueblo es posible estudiar esta campaña, mediante la presentación al presidente del Memorial de un numeroso grupo de 532 católicos pidiéndole que impida la propagación del ateísmo en las escuelas (El Pueblo, 4/10/1924). La manifestación de mujeres a la presidencia pidiéndole al presidente la destitución del secretario de instrucción pública, Octavio Méndez Pereira debido a que estaba laicizando la escuela, la denuncia de la "labor irreligiosa" de una serie de profesores y profesoras acusados de "descatolizar" a las niñas, y cuyos nombres se publicaron en una lista (entre ellos: Octavio Méndez Pereira, José D. Crespo, Elida Campodónico de Crespo) (El Pueblo, 15/1/1925). Tan importante fue esta campaña contra la enseñanza laica y la coeducación, que todavía en 1926 seguía un grupo al frente defendiéndola, ejemplo de ello fue la "Carta de Dña. Catalina Guardia de Bendetti", donde se sostienen las mismas ideas contra la coeducación, referidas en este caso a las 
discusiones que se realizaron en el Congreso Interamericano de Mujeres de ese año ( $E l$ Pueblo, 29/7/1926).

Ácidas críticas contra la coeducación se publicaban en las páginas de La Avispa (que se autodefinía como bisemanario crítico y joco-serio", dirigido por el educador José de la Cruz Herrera), basadas en la opinión de que las profundas diferencias fisiológicas entre hombres y mujeres exigían formas diferentes de educación y, además, la separación de los sexos era deseable por consideraciones de higiene mental y corporal. En términos similares se manifestaba también la publicación El Ají (La Avispa, 5/1/1922 y 22/5/1922).

\section{La polémica sobre los derechos de las mujeres y el sufragio femenino}

El debate sobre el sufragio femenino y los derechos de las mujeres se inicia a finales de 1922. En ese momento ocurren dos hechos trascendentales que hacen estallar la polémica: el primero de ellos es la presentación del diputado Pérez Venero de su proyecto de ley sobre el sufragio femenino, y el otro es la creación, casi paralelamente, en diciembre de ese año, del Grupo Feminista Renovación y el anuncio de la creación de la Sociedad Nacional para el Progreso de la Mujer. En los años subsiguientes fue cuando tuvo mayor beligerancia en la prensa, reapareciendo en la de los años treinta mucho menos, generalmente cuando alguna actividad del Partido Nacional Feminista lo ponía de nuevo sobre el tapete. Una especie de fiebre y agitación recorre la prensa nacional, en defensa o en contra de la demanda recién hecha por un numeroso grupo de mujeres de los mismos derechos políticos que los hombres. El periódico El Tiempo es uno de los más apasionados defensores y portavoces de los derechos femeninos, lo cual era impulsado en esa época por su director y gerente José D. Moscote. 
Una voz anónima, que se firma con el pseudónimo Nora, en su artículo "Feminismo" se opone al sufragismo aduciendo que las mujeres abandonarían el hogar, con los consiguientes daños para la familia y añadiendo, por otra parte, que si las mujeres alcanzaran a entrar en la política, tendrían entonces dos mandos (en la casa y en el gobierno) con lo que serían superiores a los hombres y esto sería malo también (La Estrella de Panmá, 19/12/1922). Esperanza Guardia de Miró, desde las columnas de El Tiempo, defiende la igualdad de derechos de la mujer, pero se opone a la ingerencia de la mujer en política y en un intercambio de opiniones que sostiene con un lector o lectora que se mantiene anónimo bajo el pseudónimo de Aspasia de Mileto, se manifiesta partidaria del perfeccionamiento de la mujer y el despliegue de todas sus capacidades sin olvidar nunca que su más alta misión está en su hogar. ${ }^{11}$

Entre los varones las opiniones están divididas, incluso entre los mismos liberales. Mientras Abraham Henríquez se manifiesta en su artículo "Feminismo. Por nuestras mujeres" en contra del sufragio femenino, con el argumento de la superioridad moral de las mujeres y la degradación de la política, además de la desunión que podrían crear en el hogar (La Estrella de Panamá, 21/12/1922). Otros políticos liberales, en ese mismo medio simpatizan con el sufragio y pensaban que sin esa reivindicación el feminismo se reduciría a unos cuantos tés, y unos cuantos discursos ("Sobre feminismo y sufragismo", La Estrella de Panamá, 19/1/1923). Moscote, por el contrario, se convierte en el principal adalid de éste a través de sus editoriales en El Tiempo. En un editorial titulado "La cuestión feminista" afirma que, a pesar de todos los obstáculos, prejuicios y pseudorazones que se les enfrenten y al "envejecido liberalismo" de las instituciones políticas panameñas, las mujeres alcanzarán el estado de absoluta igualdad, al igual que ya está ocurriendo en otros países donde también 
encontraron oposición (“Editorial”, El Tiempo, 28/12/1922). Moscote afirma además en su artículo "La República tiene grandes esperanzas en la mujer panameña", que no cree que “...la mujer sirva sólo para gobernar una casa: el estado también requiere sus servicios como se ve en Alemania y Estados Unidos...” (El Tiempo, 28/11/1922).

En una conferencia de Guillermo Patterson Jr., dictada en el Círculo Literario, éste expone sus ideas sobre el feminismo. Se trata de una larga conferencia, que inicia refiriéndose a la Constitución (no sin antes hacer un jocoso comentario sobre las sufragistas inglesas a quienes califica como “desheredadas de Praxíteles, con Mrs. Pankhurst a la cabeza”). Según él, Carlos A. Mendoza al redactar el artículo 49 de la Carta Fundamental tuvo la feliz idea de abrirle las puertas de la ciudadanía a las mujeres al escribir “...todos los ciudadanos...” en un sentido genérico, con lo cual la mujer está incluida también en el derecho a la ciudadanía. Al contrario de lo que ocurría en la Constitución colombiana, por el artículo 6 de la Constitución también las mujeres tienes el derecho a la nacionalidad en las mismas condiciones que el varón, y en conclusión, las mujeres pueden tener la nacionalidad, pueden ser por lo tanto ciudadanas y por lo tanto pueden ejercer el sufragio. Las panameñas no han ejercido este derecho, en su opinión, unas por ignorancia y las otras, las que sí saben, “...por una correcta interpretación de lo que es el feminismo y el convencimiento de lo innecesario que es, hoy por hoy, en Panamá...”

En su opinión, la omisión en el artículo 49 de la Constitución de la palabra "varón" no era casual, obedecía al pensamiento democrático de Mendoza, ya que en esa misma época confeccionó el Código Civil donde se le dio a la mujer la libre administración de sus posesiones y la libertad de testar. Las limitaciones de la ciudadanía de la mujer casada quedaron suspendidas al tener que utilizarse el Código Civil colombiano como base del 
derecho panameño, lo cual creó confusiones y contradicciones. De tal modo, por el hecho del matrimonio se contrae la sociedad de bienes entre los cónyuges y toma el marido la administración de los de la mujer; además, sin la autorización escrita del marido, no puede la mujer casada comparecer en juicio por sí ni por procurador y necesita la autorización del marido en causa criminal. La mujer no puede sin autorización del marido celebrar contrato alguno ni desistir de un contrato anterior, ni remitir deudas, ni aceptar o rechazar una donación, herencia o legado, ni adquirir a título alguno, onerosos o lucrativo, ni enajenar, hipotecar o empeñar. Conservaban en cambio sus derechos ciudadanos las mujeres solteras, las viudas y las divorciadas.

Un problema distinto es que las mujeres ejerzan o no sus derechos. Las leyes eleccionarias fueron otro obstáculo que impedía, no sólo a las casadas sino a todas las demás, el libre ejercicio de sus derechos al sufragio, pero ninguna mujer llevó esas leyes ante los tribunales, que, en justicia, deberían de haberlas declarado inconstitucionales y haber ordenado que se permitiera votar a las solteras, viudas y divorciadas. Desde el año 1917, el nuevo Código Civil, confeccionado por Mendoza, dio a la mujer casada la libre administración de sus bienes y eliminó todas las disposiciones contrarias, así pues la mujer casada, si no hubiera capitulaciones matrimoniales, queda dueña y señora de los bienes que tenía al contraer matrimonio y de los que adquiera durante él. Pero, a pesar de que desde 1917 ya el código civil y el administrativo están de acuerdo con la Constitución y le daban plena igualdad a la mujer panameña, el código judicial mantuvo su espíritu conservador respecto a otros derechos: el derecho a ser apoderado, la mujer sólo puede ejercer poder de sus padres, de su marido o de sus hijos, con lo cual se le niega el ejercicio del poder judicial. Él propuso una reforma que fue aprobada 1917 pero no fue publicada en la gaceta Oficial y nunca se 
deshizo este entuerto. La conclusión de su razonamiento es que considera innecesario el proyecto de ley presentado por Juan N. Venero, titulado: "Para los efectos constitucionales y legales, está incluida la mujer panameña en la expresión 'ciudadanos panameños mayores de 18 años"”, más aún, considera que este proyecto es una aceptación de la idea de que la mujer panameña no es panameña, es decir, carece de nacionalidad.

Sobre la campaña feminista, Venero se manifiesta defensor de los derechos de las mujeres, cosa que aprendió en EEUU, donde se crió, y comparte las ideas de su esposa, Angélica Chávez de Patterson, cuyas ideas y actividades en pro de la mujer son bien conocidas, incluso en 1916 discutió con Mendoza y Filós la posibilidad de poner 1 o 2 mujeres en las listas de candidatos de concejales. En su programa ideal del feminismo, Venero explica que el feminismo bien entendido no es antagonismo con los hombres, sino “colaboración inteligente con el hombre en todas las actividades de la vida", no quiere decir que las mujeres abandonen su hogar y sus hijos para hacerle frente al hombre en política, significa que la mujer debe ser "una buena esposa y una madre ejemplar que sabrá dar a la patria perfectos ciudadanos”. Según él, el sufragismo es una etapa del feminismo, el voto que persigue es sólo el vehículo para alcanzar el goce completo de la igualdad ante la ley, y “...una vez conseguida esta igualdad, cesa la necesidad del voto femenino, y si bien (las mujeres) deben conservar el derecho de sufragar, su uso que es sin duda un sacrificio y no un placer para la mujer que se estima, debe cesar en la práctica..." Para Venero, esto explica el escaso porcentaje de mujeres que votaron en las elecciones al congreso norteamericano.

El programa para el feminismo que propone Venero, considera que es el ideario que defendieron los dos grupos de mujeres que se organizaron y los que se han venido defendiendo desde la prensa. Este programa se desglosa en siete puntos: 
1. Educación igual para ambos sexos "hasta donde sea posible", para que la mujer sea una verdadera compañera intelectual del hombre y para que pueda comprender y defender sus derechos y cumplir bien sus obligaciones.

2. Enseñar a la mujer a respetarse a sí misma para que los hombres la respeten y la defiendan en todo caso.

3. Educación física para que pueda hacerse respetar por la fuerza en caso necesario sino para hacer de ella una madre adecuada de una generación sana y robusta.

4. Modelación del carácter de la mujer para que con su firmeza y rectitud impida los desvíos de sus hijos o parientes en vez de llorar desconsolada.

5. Concepto claro de caridad que el buen corazón femenino debe patrocinar, comenzando por la aplicación de principios eugénicos en cuanto a sí misma y a los suyos se refiere.

6. Igualdad ante la ley.

7. Derecho a cooperar con el hombre en política, votar y desempeñar puestos públicos o de elección popular al igual que los hombres.

Según Venero, las mujeres deben concentrarse en los cinco primeros puntos puesto que los dos siguientes deben tan sólo insistir en que los funcionarios cumplan las disposiciones legales que favorecen a las mujeres (Patterson 1923: 2). El pensamiento de Patterson expresado en estas conferencias resume el punto de vista de los liberales moderados que, aceptando el derecho de sufragio femenino, no consideraban que las mujeres debieran participar en la política ni luchar para ello. Sus tesis eran próximas a las de la Sociedad Nacional para el Progreso de la Mujer. 
En el extremo del conservadurismo estaban algunas de las opiniones sobre el sufragio femenino expresadas en cierta prensa como El Panameño. Algunos le restaban importancia al tema diciendo que el sufragio no cambiaría en nada la vida de las mujeres pues pocas de ellas ejercerían el derecho en caso de tenerlo (“seguirán siendo mujeres”), sólo votarían las mujeres que hacen de hombres y llevan el pan a su casa, para nada mejoraría la condición de las mujeres pues las mujeres ricas seguirían estando protegidas y las pobres seguirían siendo víctimas de los "seductores de los arrabales". Un articulista que se ocultaba bajo el pseudónimo de Avdey escribió “Dale que le das”, el cual debió de ser uno de los artículos más violentos contra las feministas y sus ideas, ya que él las llamaba "trastocadas mentes ilusas" que querían parecerse a los hombres apoyadas por algunos de ellos, y "formaban alharacas" como si no tuvieran nada que hacer, que "como el mico, imitan", y las insultaba por último llamándolas “amachadas” (El Panameño, 3/2/1923: 2).

El viejo liberalismo decimonónico, representado en su mejor forma en Panamá por el presidente Porras tenía una posición muy definida acerca del papel que las mujeres debían desempeñar en la sociedad, que, en su opinión, no debía transgredir nunca el ámbito de la maternidad y del hogar. Cierto que admitía una modernización y adecuación a los tiempos modernos: la mujer podía trabajar y encargarse de las tareas de beneficencia, educación y salud pública (moral, física y espiritual), de las que, además, el Estado no podía aún hacerse cargo. El derecho al sufragio estaba descartado, y así se lo manifiesta el presidente Porras a Clara González en las entrevistas y correspondencia que intercambiaron de 1922 a $1924 .^{12}$ Lo más que podía admitir eran ciertas reformas legales, por lo demás muy atrevidas para el momento, como abrir la posibilidad del ejercicio de la abogacía a las mujeres. ${ }^{13} \mathrm{Su}$ apoyo era, 
por lo tanto, a la expresión del feminismo representado por la Sociedad Nacional para el Progreso de la Mujer, y a Esther Neira de Calvo.

Entre la familias Neira y Calvo y el presidente Porras existía una vieja relación política y tenían relación personal, Porras la nombró como representante de Panamá en el Congreso de Baltimore, argumentando que “...no sólo he tenido en cuenta las simpatías que me inspira, sino sus capacidades y sus méritos, pues considero que Ud. es uno de los más altos exponentes de la cultura y de la inteligencia del sexo bello en Panamá...” Este congreso internacional fue la escuela en la que Calvo se inició en el feminismo, ella lo explica en una de sus cartas de la siguiente forma: (después de agradecerle el nombramiento) “...Veo en este acto de bondad suya, el reflejo de su cariño noble y desinteresado por Raúl (su esposo) y por mí ...He rectificado mucho mi anterior criterio acerca de lo que el movimiento feminista significa. Sería muy largo entrar en detalles pero sí le aseguro que estoy aprendiendo mucho y que hasta ahora nada me ha chocado..."

Por las razones variadas que hemos visto, que coincidían con las de las mujeres de la Sociedad, este sector de los políticos liberales, se constituirían en los aliados políticos de la Sociedad Nacional para el Progreso de la Mujer, y se oponían al sufragio femenino. El otro sector de aliados que tenía la Sociedad Nacional para el Progreso de la Mujer era los liberales que estando de acuerdo con el principio de igualdad, en la práctica no estaban dispuestos a concederles a las mujeres sus derechos ciudadanos.

De otro lado, el sector más moderno del liberalismo, expresado principalmente por Eusebio A. Morales, José D. Moscote, Jeptha B. Duncan, José D. Crespo y por el entonces ya difunto Carlos A. Mendoza, que, a fuer de liberal, llega a ser el "liberalismo socializante" del que habla Ricaurte Soler, lucha en esos momentos por extender la democracia en Panamá, es 
decir la igualdad y las libertades públicas. ${ }^{15} \mathrm{Y}$ para ellos, era imposible cualquier avance democrático que no incluyera la participación plena social y política de la mujer, y, como consecuencia, el derecho al sufragio. Este sector se convertirá en aliado natural del Partido Nacional Feminista, cuyo programa defenderá en todas las posiciones en que se encontraban, cuando estuvieron en el poder político desde allí (por ejemplo, cuando Duncan fue secretario de instrucción pública, en su defensa de la coeducación), desde sus puestos de educadores, y desde las tribunas de la prensa y de las conferencias. Este apoyo fue reconocido por las mujeres del PNF (cuando aún eran Grupo Feminista Renovación) que los nombraron presidentes honorarios de su organización.

Otros aliados políticos de este sector del feminismo eran algunas de las agrupaciones e individualidades anarquistas y socialistas que se agitaban en el incipiente movimiento obrero nacional. Es bastante conocido que la Federación Obrera de Panamá, en su programa de 1921, incluía la reivindicación del sufragio femenino. Desde 1911 se detectan intervenciones femeninas dentro de los pequeños grupos anarquistas que existieron en el país, pero, hasta donde se sabe, no reivindicaron el sufragio femenino (como, por otra parte, es lógico en esa corriente obrera), porque estaban en contra de la participación en la lucha parlamentaria.

José María Blázquez de Pedro sostuvo un decidido apoyo hacia feminismo más radical, el que no debía conformarse con el derecho al voto sino el que lo exigía todo, basado en dos pilares: la independencia económica y en la libertad sexual y amorosa (Blázquez de Pedro 1922). De las filas del movimiento obrero sabemos que se incorporaron miembros de la Unión Obrera Femenina al Grupo Feminista Renovación y también que tuvo una participación destacada Julia Palau de Gámez, quien, desde 1910, estaba relacionada con los grupos obreros organizados. $^{16}$ 
Pero, también entre el sector obrero tuvo el sufragio femenino opositores, uno de sus exponentes Narciso Navas adujo en su artículo editorial “¿Debe votar la mujer?”, que la mujer se convertiría en competidora y enfrentada al hombre con lo que se pondría en peligro la causa de las clases desvalidas. Además, la mujer no necesita el sufragio porque la pueden apoyar y proteger la clase trabajadora e intelectuales progresistas. El sufragio es un medio de esclavizar a los hombres y también a las mujeres; y la razón más poderosa: la lucha verdadera debe hacerse por las clases oprimidas, sin distinción de sexo, la opresión es del capitalismo hacia los productores, hombres y mujeres, el sufragio dividiría a la clase y la debilitaría (Narciso Navas, 17/5/1923).

\section{CONCLUSIONES}

El feminismo y el sufragismo de comienzos de siglo tuvieron un papel de gran influencia en los cambios que sucedieron en la imagen y el papel de las mujeres en la misma época, el mismo que estaba sucediendo en todo el mundo occidental y que las panameñas conocieron al tener la oportunidad de estudiar, de viajar a otros países, también con el ejemplo de las mujeres de la Zona del Canal y a través de los medios de comunicación. Los cambios que exigían las mujeres en la legislación se correspondían a los nuevos roles a los que ellas sabían que tenían derecho y que pensaban además que debían desempeñar en la sociedad moderna, en un mundo que cambiaba rápidamente.

Tales demandas iban a transformar profundamente las relaciones entre los sexos, las familias y las estructuras políticas y sociales. Quizás la más grande de las transformaciones era la idea, practicada por las feministas y especialmente por las sufragistas, de la libertad femenina para pensar y decidir por ellas mismas acerca de todo lo que les concernía, acerca de 
lo bueno y lo malo. Por ello encontraron gran oposición entre los hombres y sus organizaciones de poder. Otro factor de oposición fue, posteriormente, ya en la década de los años treinta, que el patriarcado liberal, instalado en el poder, fue muy reacio en su mayoría a acceder a la emancipación femenina por el miedo que le producía la reordenación política a que necesariamente obligaría la prácticamente duplicación del electorado y la falta de control sobre esa situación nueva, a la vez que por el miedo a los cambios que podían sucederse en el seno de sus hogares.

\section{BIBLIOGRAFÍA CONSULTADA}

Alma. 1919a. “La inercia femenil”, en el Diario de Panamá, 27 de abril. . 1919b. "La modalidad", en el Diario de Panamá, 4 de mayo. . 1919c. "El lenguaje", en el Diario de Panamá, 20 de abril. . 1919d. "La salud como base de la belleza", en el Diario de Panamá, 11 de mayo.

. 1919e. "La armonía conyugal", en el Diario de Panamá, 1 de junio.

Blázquez de Pedro, José María. 1921. "El feminismo completo“, en el El Tiempo, 5 de enero.

Collante, Lola. 1920a. "Al oído de mis hermanas de América“, en revista Cuasimodo, $\mathrm{N}^{\circ} 8$, marzo.

. 1920b. "Socialismo en Colombia", en revista Cuasimodo, № 10, mayo.

1920c. "Desde la tribuna de Cuasimodo", $\mathrm{N}^{\circ} 11$, junio.

1920d. "Panamericanismo", en revista Cuasimodo, No 13, agosto.

1922. Mis inquietudes, Talleres Gráficos de "El Tiempo", Panamá.

1925. "Mientras el mundo gira con un pequeño descendente", en La Estrella de

Panamá, 2 de septiembre.

Cott, Nancy F. 2000. "La mujer moderna, estilo norteamericano: los años veinte", en Georges Duby y Michelle Perrot: Historia de las mujeres, 5. El siglo XX, Grupo Santillana de Ediciones, S. A., Madrid.

Delgado Hernández, H. 1921. “Lola Collante“, Diario de Panamá, 18 julio.

Duby, Georges y M. Perrot. 2000. Historia de las mujeres. 5. El siglo XX, Grupo Santillana de Ediciones, S.A., Col. Taurus-Minor. Madrid.

Grazia, Victoria de. 2000. "Patriarcado fascista: las italianas bajo el gobierno de Mussolini, 1922-1940”, en Duby y Perrot, Historia de las mujeres, 5.

Lavrin, Asunción. 1999. "Recordando la génesis del sufragio", texto inédito de una conferencia dada por la autora en la Universidad de Costa Rica, agosto. 
Marco Serra, Yolanda. 1993. "El nacimiento del movimiento feminista en Panamá, 1923”, Revista Humanidades, Fac. Humanidades, Universidad de Panamá, Panamá. . 1997a. "El feminismo de los años veinte y la redefinición de la femineidad en Panamá", en Eugenia Rodríguez, ed., Entre silencios y voces -Género e historia en América Central (1750-1990)-, San José: Centro Nacional para el Desarrollo de la Mujer y la Familia, pp. 183-196.

Marco, Yolanda y Alvarado, Angela. 1997b. Mujeres que cambiaron nuestra historia, Panamá: IMUP, Universidad de Panamá-UNICEF. . 2000. Mujeres parlamentarias en Panamá, 1945-1995, Panamá: IMUPPROIGUALDAD. . 2002a. "El movimiento sufragista en Panamá y la construcción de la mujer moderna", Yolanda Marco, coord., Historia de los movimientos de mujeres en Panamá en el siglo XX, Panamá: Instituto de la Mujer de la Universidad de Panamá, PROIGUALDAD, 2002, pp. 45-132. . 2002b. "Mujeres y política educativa en Panamá a inicios del siglo XX", en Eugenia Rodríguez, ed., Mujeres, Género e Historia en América Central durante los Siglos XVIII, XIX y XX, San José: Plumsock Mesoamerican Studies, UNIFEM, pp. 5370 .

. 2002c. "Ser ciudadana en Panamá en la década de los años treinta", en Eugenia Rodríguez, ed., Un Siglo de Luchas Femeninas en América Latina, San José: Editorial Universidad de Costa Rica, pp. 71-86.

Muñoz, María Rosa. 2001. "Historia Eclesiástica. Monseñor Guillermo Rojas y Arrieta, primer arzobispo de Panamá", ponencia presentada en el Congreso Científico Nacional, Universidad de Panamá.

Patterson Jr., Guillermo. 1923. "El feminismo en Panamá -Dedicado a las feministas panameñas-", en El Tiempo, 5 de enero.

Santamaría, José D. 2000. La mujer panameña y sus derechos políticos, 1920-1946, Editorial Universitaria, Panamá.

Sohn, Anne-Marie. 2000. "Los roles sexuales en Francia y en Inglaterra: una transición suave", de Anne-Marie Sohn, en G. Duby y M. Perrott, Historia de las mujeres, 5.

Soler, Ricaurte. 1988. El pensamiento político en los siglos XIX y XX - Estudio introductorio y antología-, Biblioteca de la Cultura Panameña, Universidad de Panamá.

\section{PERIÓDICOS Y REVISTAS}

El Diario de Panamá Octubre y Noviembre de 1915; Abril-Agosto de 1919; Julio de 1921 y Enero de 1923.

El Diario Nacional: Septiembre y Diciembre de 1920.

El Obrero: Diciembre de 1921.

El Panameño: Enero y Febrero de 1923.

El Pueblo: Octubre de 1924; Enero de 1925 y Julio de 1926.

El Tiempo: Noviembre y Diciembre de 1922; Enero de 1923 y Junio de 1926.

La Avispa: Enero y Mayo de 1922.

La Estrella de Panamá: Diciembre de 1922; Enero y Febrero de 1923; Septiembre y Diciembre de 1925 y Mayo y Junio de 1926. 
Cuasimodo, Magazine: Junio de 1919; Marzo, Mayo, Junio y Agosto de 1920. Orientación Feminista. Revista del Partido Nacional Feminista, No. 6 de junio de 1926. The Star and Herald: Marzo de 1923 y Junio de 1926.

\section{NOTAS}

${ }^{1}$ Tomamos el concepto de patriarcado liberal en el sentido que le otorga Victoria de Grazia. Grazia lo define así: “.... [es] el régimen opresivo de relaciones de género predominante en las sociedades occidentales durante el siglo $\mathrm{XX}$, ...basado en la minimización del consumo y un ejercicio restringido de los derechos de ciudadanía, y con el refuerzo de una ideología de escasez, el liberalismo europeo anterior a la Primera guerra Mundial había medrado exigiendo a sus súbditos estricta disciplina social y costumbres puritanas. El gran movimiento de emancipación que surgió entre las mujeres europeas (ya visible en los movimientos sufragistas de preguerra), y con raíces más profundas en la revolución demográfica y en la expansión de las ideas liberales a mediados del siglo XIX, se hizo irreversible una vez movilizadas millones de mujeres de acuerdo con las exigencias de la economía de guerra..." (Grazia. 2000: 159-160).

${ }^{2}$ El Diario de Panamá de octubre de 1915 tenía entre los miembros de su Cuerpo de Redacción a Ricardo Miró y a J.B. Duncan.

3 A título de ejemplo mencionaremos: "La moda al día" por la feminista española Carmen de Burgos (1/11/15), "Elegancias y coqueterías" por Salomé Núñez y Topete (1/11/15), "Impresiones de París -Moda y guerra-“, por M. Ciges Aparicio.

${ }^{4}$ En el artículo "Congreso internacional feminista. A favor de la paz, las delegadas. Actitud de las francesas. La verdadera opinión de las inglesas. Un deseo bueno y un congreso estéril" (13/11/15), firmado por la Marquesa de Crespón. El artículo informa de la iniciativa holandesa del congreso que se celebró en La Haya, y enfatiza la división de las delegaciones de los diversos países presentes, mencionando la opinión de Christabel Pankhurst, quien, a nombre propio y de su madre, protesta por este congreso que no considera representativo ya que, según ellas, la guerra debería ser proseguida "por las mujeres, por el conjunto de la humanidad, por la libertad y la belleza (...) hasta que el dominio alemán en Europa sea una aspiración imposible". Los ecos del feminismo internacional, de la división entre feministas "nacionalizadas" por la guerra mundial y las feministas pacifistas aparecen con toda claridad en este artículo.

${ }^{5}$ En la sección "Notas y noticias" bajo el epígrafe "Para las damas", el 22/11/15.

${ }^{6}$ Conviene recordar aquí que en 1916 un grupo de maestras había creado el Club Ariel, del que formaban parte sólo mujeres, con fines culturales, artístico y educativos.

${ }^{7}$ Guillermo Patterson Jr. afirma que Enriqueta R. Morales escribía en El Diario de Panamá, e identifica a Esperanza Guardia de Miró como la autora de los artículos publicados en La Estrella de Panamá bajo el pseudónimo de Clara (a la que identificamos erróneamente en otro trabajo como Clara González) (Patterson. 1923). María Isabel Mendoza, secretaria de Enriqueta R. Morales en la Cruz Roja nos habló en una entrevista de que ésta era redactora de "las sociales" en varios periódicos y en varias épocas.

${ }^{8}$ El ambiente intelectual de esos años, así como el papel que desempeñaba en él Lola Collante nos fue descrito por Diógenes de la Rosa en la entrevista realizada en 1996.

${ }^{9}$ Según A. Lavrin, las feministas latinoamericanas defendieron la femineidad como parte esencial del feminismo y como elemento no discorde con el ejercicio de la ciudadanía, haciendo una limpieza sanitaria de la femineidad como sumisión y convirtiéndola en agente de cooperación con el hombre y cambio de la sociedad. Eso les permitió granjearse el apoyo de los hombres y, a la vez, descubrir otra faceta de la femineidad, la femineidad al servicio de la nación que con la dulzura, sensibilidad, dedicación y amor, podía ser un agente de cambio social, de legislación en pro de madres e hijos, de reforma y moralización del proceso político mismo (Lavrin. 1999:11).

${ }^{10}$ La propiedad el periódico pasó en febrero de 1920 a manos de Tomás Gabriel Duque, propietario también de La Estrella de Panamá, pero todavía se mantuvo como director-gerente José D. Moscote un tiempo más hasta que poco después lo dejó y pasó a trabajar en el periódico El Tiempo, propiedad de Jeptha B. Duncan, que fue 
otro de los grandes defensores de los derechos femeninos. Ver en El Diario de Panamá, los editoriales del 10 de junio de 1919, del 2 de julio de ese mismo año y las del 4 de agosto, por ejemplo.

${ }^{11}$ Esperanza Guardia de Miró es una de las pocas mujeres que escribía en la prensa, durante un tiempo y bajo la firma de Clara escribió sobre el feminismo en las páginas de La Estrella de Panamá. Su polémica con Aspasia de Mileto en El Tiempo se desarrolló en los días siguientes al 21 de diciembre de 1922, en que publicó en ese periódico el artículo titulado "Habla la mujer panameña".

${ }^{12}$ La correspondencia entre Clara González y Belisario Porras se puede estudiar en la Serie 2-10, Tomo XIII, Año 1922, Folio 579. Cartas Generales, letra G, y la Serie 2-11, Tomo XIV, año 1923, Folio 678, Cartas generales, letra $\mathrm{G}$ de los Archivos Porras.

${ }^{13}$ En la correspondencia antes mencionada se puede estudiar el proceso de reforma de la ley sobre el ejercicio de la abogacía a partir de la solicitud de Clara González al presidente Porras en agosto de 1922 que, finalmente y después de muchas vicisitudes, culminará con la reforma de la ley en la Asamblea en abril de 1924.

${ }^{14}$ Correspondencia entre Esther Neira de Calvo y el presidente Belisario Porras, de febrero a mayo de 1922. En Serie210, Tomo VII, año 1922, Folio 534, 079 y 080, Cartas Generales, letra C. Archivos Belisario Porras.

${ }^{15}$ Ver por ejemplo dos de las expresiones más acabadas de este pensamiento: "El liberalismo como actitud mental y como doctrina" de Moscote y "Doctrinas maximalistas" de Morales, en Ricaurte Soler (Soler. 1988).

${ }^{16}$ Según Manuel V. Garrido, que laboraba con Gámez en los Talleres-Escuela, ésta expuso por primera vez su proyecto de talleres-escuela para enseñar alguna profesión a las mujeres pobres, con la finalidad de obtener su ayuda, ante asociaciones obreras en una conferencia en 1910 en la Sociedad de Concordia, más tarde, en 1912, en la Sociedad de Hijas del Hogar, y mantuvo correspondencia con organizaciones similares en Estados Unidos (la Srta. Betris Melweer) y otras organizaciones feministas ( ver: Presidencia. Cartas Generales. Letra G. 1923. Tomo XIV, Serie 2-11, A-215, Archivos Porras). Con estos antecedentes no extraña que Julia Palau de Gámez se sumara con entusiasmo al Grupo Feminista Renovación y mantuviera toda su vida la relación con el PNF hasta su muerte a comienzos de los años 40 . 